\title{
EVALUATION OF GE(Li) COMPTON SUPPRESSION SPECTROMETERS FOR NONDESTRUCTIVE RADIOCHEMICAL ANALYSIS
}

\author{
J. A. Cooper
}

August 1970

\section{AEC RESEARCH \& DEVELOPMENT REPORT}




\section{LEGAL NOTICE}

This report was prepared as an account of work sponsored by the United States Government. Neither the United States nor the United States Atomic Energy Commission, nor any of their employees, nor any of their confractors, subcontractors, or their employees, makes any warranty, express or implied, or assumes any legal liability or responsibility for the accuracy, completeness or usefulness of any information, apparatus, product or process disclosed, or represents that its use would not infringe privately owned rights.

\section{PACIFIC NORTHWEST LABORATORY}

RICHLAND, WASHINGTON

operated by

BATTELLE MEMORIAL INSTITUTE

for the

UNITED STATES ATOMIC ENERGY COMMISSION UNDER CONTRACT AT(45-1)-1830 
EVALUATION OF GE(Li) COMPTON SUPPRESSION SPECTROMETERS FOR NONDESTRUCTIVE RADIOCHEMICAL ANALYSIS

By

J. A. Cooper

Radiological Sciences Department Environmental and Life Sciences Division

August 1970

BATTELLE MEMORIAL INSTITUTE PACIFIC NORTHWEST LABORATORIES RICHLAND, WASHINGTON 99352 
BNWL - 1285

Printed in the United States of America Available from

Clearinghouse for Federal Scientific and Technical Information National Bureau of Standards, U.S. Department of Commerce Springfield, Virginia 22151

Price: Printed Copy $\$ 3.00 ;$ Microfiche $\$ 0.65$ 


\title{
EVALUATION OF Ge(Li) COMPTON SUPPRESSION SPECTROMETERS FOR NONDESTRUCTIVE RADIOCHEMICAL ANALYSIS
}

\author{
J. A. Cooper
}

\section{AB S TRACT}

Ge(Li) Compton suppression spectrometers are evaluated relative to the specific needs of the analytical radiochemist. Their application to the analysis of radionuclides found in neutron activation, fission product, and environmental radionuclide analyses is discussed. 
BNWL -1285

EVALUATION OF Ge(Li) COMPTON SUPPRESSION SPECTROMETERS FOR NONDESTRUCTIVE RADIOCHEMICAL ANALYSIS

J. A. Cooper

INTRODUCTION

This report evaluates Ge(Li) Compton suppression spectrometers as they apply to the work of the analytical radiochemist. A large number of sophisticated Ge(Li) Compton-suppression spectrometers (1-19) have been developed and evaluated relative to their basic performance parameters. However, they have not been evaluated relative to the specific needs of the analytical radiochemist. All of these spectrometers can provide an improved peak-to-Compton ratio for a pure radionuclide, but this is not always accompanied by an improvement in the sensitivity for the nondestructive measurement of radionuclides in complex mixtures.

\section{SUMMARY}

Ge(Li) Compton suppression spectrometers are evaluated relative to the specific needs of the analytical radiochemist. The Compton-summing spectrometers are shown to have a very limited range of applicability. They are not applicable to low-level counting and their application to high-level samples is questionable. The anticoincidence-shielded spectrometers with the source located outside the shield provide uniquely superior performance for decay scheme studies and high level samples which can't be subdivided; however, they are not applicable to low-level samples. The shielded spectrometers with the source positioned inside the shield appear to have the most general application to radioanalytical problems.

\section{DISCUSSION}

The sensitivity of a gamma-ray spectrometer is a measure of its ability to detect gamma rays in the presence of interference from natural radioactivity and the compton continuum 
from higher energy gamma rays. The sensitivity is of the greatest concern when this interference is greater than, or of the same order of magnitude as the peak. This general problem is illustrated in Figure 1, which shows a peak superimposed on a flat background before and after background suppression. The accuracy, or sensitivity, will be improved if the fractional error before background suppression $(\sigma / N)$ is greater than the fractional error after background suppression $\left(\sigma^{\prime} / N^{\prime}\right)$. That is, the background suppression device will improve the sensitivity if the ratio of the fractional error before to the fractional error after background suppression is greater than 1. However, since the full-energy peak detection efficiency is usually reduced along with the background interference, the magnitude of the improvement will depend not only on the background suppression, but also on the peak efficiency reduction factor (e), the initial peak-to-background ratio (R), and the improvement in the peak-to-background ratio (r) .

Galloway (20) has derived the following equation relating these basic parameters to the ratio of the accuracy (A) before background suppression to the accuracy $\left(\mathbf{A}^{1}\right)$ after background suppression $\left(\mathrm{A} / \mathrm{A}^{\prime}\right)$ :

$$
A / A^{\prime}=\{[\operatorname{er}(R+2)] /(r R+2)\}^{1 / 2}
$$

The dependence of this ratio on $e, r$, and $R$ is illustrated in Figure 2. The dashed line at A/A' equal to 1 divides the improved and reduced sensitivity regions. There will be an improvement in the sensitivity after background reduction for those parameter values for which A/A' is above the broken line. This figure shows that for large initial peak-to-background ratios (R), the ratio of A/A' approaches 1 for e values of 1 . Thus, the improvement in sensitivity is rather insignificant for large initial peak-to-background ratios. On the other hand, the most dramatic improvements in sensitivity are obtained when $\mathbf{R}$ is small: i.e., when the peak of interest is difficult or impossible to detect because of Compton or background interference. 
BNWL- 1285

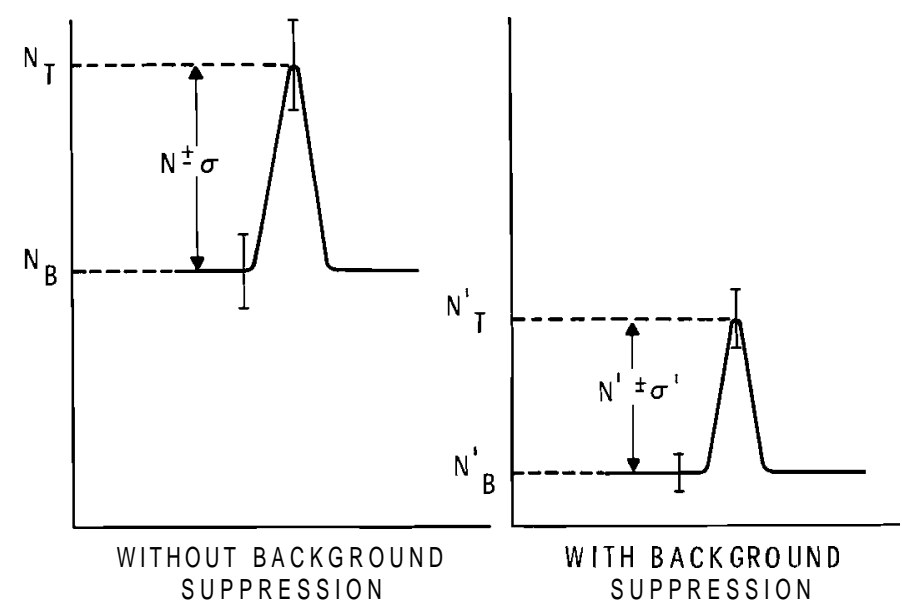

FIGURE 1. A Peak on a Smooth Background Before and After Background Suppression(20)

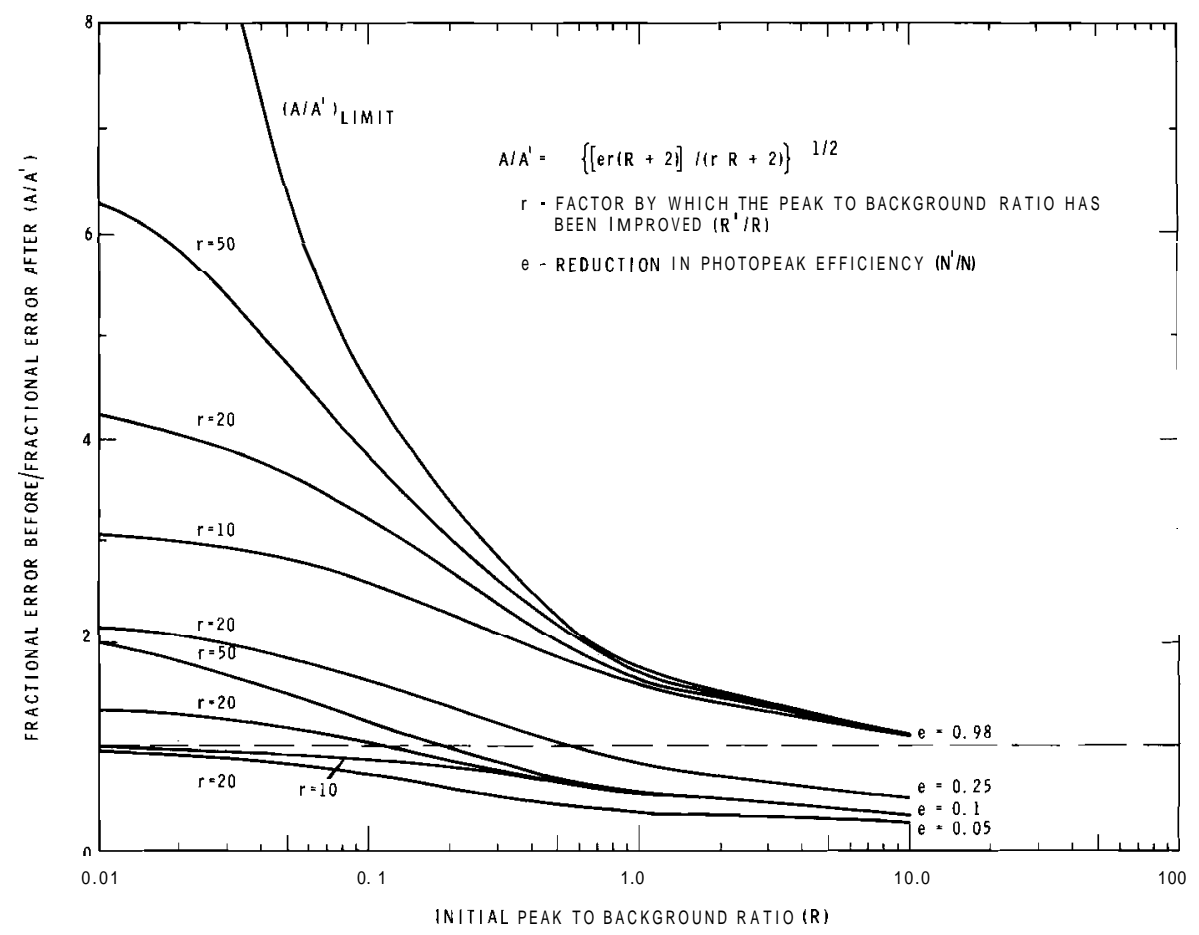

FIGURE 2. A Plot of the Ratio of the Fractional Error Before to the Fractional Error After Background Suppression Versus the Initial Peak-to-Background Ratio(20) 
The importance of maintaining a high peak efficiency while reducing the background is also illustrated in Figure 2. For example, if $e=0.1$ (i.e., if the peak efficiency is reduced by a factor of 10 , as is often the case with the Ge(Li) Comptonsumming systems), the background must be reduced by more than a factor of 100 before any improvement in sensitivity can be achieved $(\mathrm{r}=10, \mathrm{e}=0.1)$. On the other hand, if the peak efficiency is not reduced at all (i.e., e $=1$ ), then any reduction in the background will improve the sensitivity. However, the magnitude of the improvement will depend not only on the amount of background reduction, but also on the initial peak-tobackground ratio. Thus, one of the most important factors to consider when evaluating Compton suppression techniques is the reduction in peak efficiency accompanying the Compton suppression.

Ge(Li) Compton-suppression spectrometers can be divided into two basic categories: (1) the all Ge(Li) Compton-summing systems, $(10-16)$ and (2) the anticoincidence-shielded Ge(Li) systems $(1-9,17)$ which can be subdivided into those systems with the source located inside the shield (ACS-in) and those with the source outside the shield (ACS-out). The a 11 Ge(Li) Comptonsumming spectrometers utilize two Ge(Li) detectors which are operated in a sum-coincidence mode, while the anticoincidenceshielded spectrometers reject diode pulses resulting from gamma rays which have deposited a fraction of their energy in both the diode and scintillator.

The reciprocal of the peak reduction factors (1/e) for some of those radionuclides of interest to the analytical radiochemist have been calculated for the ACS-in system and are 1 isted in Tables 1,2 and 3 . The reduction factors were determined by estimating the difference between the normal and Compton suppressed count rates for the most intense peak in the normal spectrum. This was determined from the radionuclide decay scheme and the anticoincidence shield efficiency. (17) 
TABLE 1. Inverse Reduction Factors for Radionuclides Produced by Neutron Activation

\begin{tabular}{|c|c|c|}
\hline Radionuclides & $\underline{E y, k e V}$ & $\begin{array}{c}\text { Inverse Reduction } \\
\text { Factor, } 1 / \mathrm{e} \\
\end{array}$ \\
\hline $\mathrm{Na}-24$ & 1369 & 4 \\
\hline Mg- 27 & 842 & 1.0 \\
\hline A1- 28 & 1780 & 1.0 \\
\hline $\mathrm{Si}-31$ & 1260 & 1.0 \\
\hline$S-37$ & 3090 & 1.0 \\
\hline $\mathrm{C} 1-38$ & 1645 & 5 \\
\hline$K-42$ & 1524 & 1.0 \\
\hline$S C-46$ & 889 & 7 \\
\hline $\mathrm{Ca}-47$ & 1300 & 1.0 \\
\hline$S C-47$ & 160 & 1.0 \\
\hline $\mathrm{Ca}-49$ & 3100 & 1.0 \\
\hline Cr- 51 & 320 & 1.0 \\
\hline Ti-51 & 320 & 1.0 \\
\hline$V-52$ & 1434 & 1.0 \\
\hline$M n-54$ & 835 & 1.0 \\
\hline$M n-56$ & 847 & 2 \\
\hline $\mathrm{Fe}-59$ & 1095 & 1.0 \\
\hline $\mathrm{Co}-60$ & 1173 & 7 \\
\hline $\mathrm{Cu}-64$ & 511 & 20 \\
\hline $\mathrm{Ni}-65$ & 1481 & 1.0 \\
\hline $\mathrm{Zn}-65$ & 1115 & 1.0 \\
\hline$Z n-69 m$ & 439 & 1.0 \\
\hline Ga- 70 & 1040 & 1.5 \\
\hline $\mathrm{Ga}-72$ & 835 & 20 \\
\hline $\mathrm{Ge}-75$ & 265 & 1.0 \\
\hline $\mathrm{Se}-75$ & 401 & 20 \\
\hline As -76 & 559 & 1.2 \\
\hline $\mathrm{Br}-82$ & 554 & 65 \\
\hline $\mathrm{Sr}-85$ & 514 & 1.0 \\
\hline $\mathrm{Rb}-86$ & 1078 & 1.0 \\
\hline
\end{tabular}


TABLE 1. (Contd)

\begin{tabular}{|c|c|c|}
\hline Radionuclides & $\underline{E y}, \mathrm{keV}$ & $\begin{array}{c}\text { Inverse Reduction } \\
\text { Factor, l/e } \\
\end{array}$ \\
\hline$S r-87 m$ & 388 & 1.0 \\
\hline$Y-90$ & 1750 & 1.0 \\
\hline $\mathrm{Zr}-95$ & 724 & 1.0 \\
\hline$z r-97$ & 747 & 1.0 \\
\hline Mo-99 & 740 & 1.0 \\
\hline Tc- $99 \mathrm{~m}$ & 143 & 1.0 \\
\hline$R u-103$ & 497 & 1.0 \\
\hline$R u-105$ & 726 & 1.1 \\
\hline $\mathrm{Rh}-104 \mathrm{~m}$ & 555 & 1.1 \\
\hline $\mathrm{Ag}-108$ & 633 & 1.0 \\
\hline$P d-109$ & 88 & 1.0 \\
\hline$P d-109 m$ & 188 & 1.0 \\
\hline $\mathrm{Ag}-110 \mathrm{~m}$ & 658 & 50 \\
\hline$S n-113$ & 393 & 1.0 \\
\hline In- $114 \mathrm{~m}$ & 192 & 1.0 \\
\hline$C d-115$ & 530 & 1.0 \\
\hline In-115m & 335 & 1.0 \\
\hline $\mathrm{Te}-121$ & 573 & 1.0 \\
\hline $\mathrm{Te}-121 \mathrm{~m}$ & 212 & 1.0 \\
\hline $\mathrm{Sb}-122$ & 564 & 1.1 \\
\hline $\mathrm{Sb}-124$ & 603 & 4 \\
\hline $\mathrm{I}-128$ & 441 & 1.1 \\
\hline $\mathrm{Ba}-131$ & 216 & 1.4 \\
\hline $\mathrm{Cs}-134$ & 605 & 10 \\
\hline $\mathrm{La}-140$ & 1596 & 10 \\
\hline $\mathrm{Ce}-141$ & 145 & 1.0 \\
\hline Pr-142 & 1570 & 1.0 \\
\hline$N d-147$ & 531 & 1.0 \\
\hline$E u-152$ & 344 & 8 \\
\hline $\mathrm{Eu}-152 \mathrm{~m}$ & 963 & 5 \\
\hline Gd-153 & 99 & 1.0 \\
\hline
\end{tabular}




\section{BNWL -1285}

TABLE 1. (Contd)

\begin{tabular}{|c|c|c|}
\hline$\underline{\text { Radionuclides }}$ & $\underline{E y}, \mathrm{keV}$ & $\begin{array}{c}\text { Inverse Reduction } \\
\text { Factor, } 1 / \mathrm{e} \\
\end{array}$ \\
\hline Sm-153 & 103 & 1.5 \\
\hline Gd-159 & 363 & 1.0 \\
\hline $\mathrm{Tb}-160$ & 966 & 8 \\
\hline Dy-165 & 95 & 1.0 \\
\hline$Y b-169$ & 198 & 20 \\
\hline $\mathrm{Tm}-170$ & 84 & 1.0 \\
\hline Er-171 & 308 & 20 \\
\hline Yb-175 & 396 & 1.0 \\
\hline $\mathrm{HI}-181$ & 482 & 8 \\
\hline $\mathrm{Ta}-182$ & 100 & 40 \\
\hline W-187 & 685 & 1.3 \\
\hline $\mathrm{Re}-188$ & 155 & 1.1 \\
\hline $0 s-191$ & 129 & 1.2 \\
\hline $\operatorname{Ir}-192$ & 317 & 20 \\
\hline $\mathrm{Hg}-197$ & 191 & 1.3 \\
\hline Pt- 197 & 191 & 1.3 \\
\hline $\mathrm{Au}-198$ & 412 & 1.0 \\
\hline $\mathrm{Hg}-203$ & 280 & 1.0 \\
\hline $\mathrm{Pa}-233$ & 312 & 1.3 \\
\hline $\mathrm{Np}-239$ & 278 & 3 \\
\hline $\mathrm{U}-239$ & 75 & 1.0 \\
\hline
\end{tabular}


TABLE 2. Inverse Reduction Factors for Fission Products

\begin{tabular}{|c|c|c|}
\hline Radionuclides & $\mathrm{E} \gamma, \mathrm{keV}$ & $\begin{array}{c}\text { Inverse Reduction } \\
\text { Factor: } 1 / e \\
\end{array}$ \\
\hline $\mathrm{zn}-72$ & 145 & 1.0 \\
\hline $\mathrm{Ga}-72$ & 835 & 20 \\
\hline $\mathrm{Ga}-73$ & 295 & 1.1 \\
\hline $\mathrm{Ga}-74$ & 596 & 5 \\
\hline $\mathrm{Ge}-75$ & 265 & 1.0 \\
\hline As -76 & 559 & 1.2 \\
\hline $\mathrm{Ge}-77$ & 210 & 20 \\
\hline As -77 & 240 & 1.0 \\
\hline $\mathrm{Ge}-78$ & 277 & 1.0 \\
\hline As -78 & 614 & 1.8 \\
\hline As -79 & 96 & 1.0 \\
\hline $\mathrm{Br}-80$ & 618 & 1.0 \\
\hline $\mathrm{Se}-81$ & 280 & 5 \\
\hline $\mathrm{Br}-82$ & 554 & 65 \\
\hline $\mathrm{Se}-83$ & 360 & 20 \\
\hline $\mathrm{Br}-83$ & 530 & 1.0 \\
\hline $\mathrm{Br}-84$ & 880 & 5 \\
\hline $\mathrm{Kr}-85$ & 514 & 1.0 \\
\hline $\mathrm{Rb}-86$ & 1078 & 1.0 \\
\hline$K r-87$ & 403 & 1.4 \\
\hline$K-88$ & 191 & 1.4 \\
\hline $\mathrm{Rb}-88$ & 898 & 7 \\
\hline Sr-91 & 728 & 1.4 \\
\hline$Y-91$ & 1210 & 1.0 \\
\hline$Y-91 \mathrm{~m}$ & 551 & 1.0 \\
\hline Sr-92 & 1370 & 1.0 \\
\hline$Y-92$ & 934 & 4 \\
\hline$Y-93$ & 267 & 1.4 \\
\hline$Z r-95$ & 724 & 1.0 \\
\hline $\mathrm{Nb}-95$ & 765 & 1.0 \\
\hline
\end{tabular}




\section{TABLE 2. (Contd)}

\begin{tabular}{|c|c|c|}
\hline Radionuclides & $\underline{\mathrm{Ey}}, \mathrm{keV}$ & $\begin{array}{c}\text { Inverse Reduction } \\
\text { Factor, } 1 / e\end{array}$ \\
\hline $\mathrm{Nb}-96$ & 778 & 20 \\
\hline$z r-97$ & 747 & 1.0 \\
\hline $\mathrm{Nb}-97$ & 665 & 1.0 \\
\hline $\mathrm{Nb}-98$ & 787 & 20 \\
\hline Mo-99 & 740 & 1.0 \\
\hline Tc-99m & 143 & 1.0 \\
\hline$R u-103$ & 497 & 1.0 \\
\hline$R u-105$ & 726 & 1.1 \\
\hline$R h-105$ & 319 & 1.0 \\
\hline $\mathrm{Rh}-106$ & 512 & 2.0 \\
\hline$R h-107$ & 305 & 1.0 \\
\hline $\mathrm{Ag}-111$ & 342 & 1.0 \\
\hline$P d-112$ & 617 & 2.0 \\
\hline$C d-115$ & 530 & 1.0 \\
\hline$C d-115 m$ & 935 & 1.2 \\
\hline $\mathrm{Sn}-123 \mathrm{~m}$ & 160 & 1.0 \\
\hline $\operatorname{sn}-125$ & 1068 & 10 \\
\hline $\mathrm{Sn}-125 \mathrm{~m}$ & 325 & 1.0 \\
\hline $\mathrm{Sb}-125$ & 427 & 1.0 \\
\hline $\mathrm{I}-128$ & 441 & 1.1 \\
\hline $\mathrm{Te}-129 \mathrm{~m}$ & 455 & 1.0 \\
\hline $\mathrm{I}-130$ & 538 & 20 \\
\hline $\mathrm{Te}-131$ & 150 & 1.1 \\
\hline $\mathrm{Te}-131 \mathrm{~m}$ & 780 & 20 \\
\hline I - 131 & 364 & 1.0 \\
\hline $\mathrm{I}-132$ & 669 & 15 \\
\hline $\mathrm{Te}-132$ & 230 & 1.0 \\
\hline $\mathrm{Te}-133 \mathrm{~m}$ & 432 & 20 \\
\hline $\mathrm{Xe}-133$ & 81 & 1.0 \\
\hline $\mathrm{Xe}-133 \mathrm{~m}$ & 233 & 1.0 \\
\hline
\end{tabular}


TABLE 2. (Contd)

\begin{tabular}{|c|c|c|}
\hline Radionuclides & $\underline{\mathbf{E y}, \mathrm{keV}}$ & $\begin{array}{c}\text { Inverse Reduction } \\
\text { Factor, } 1 / \mathrm{e}\end{array}$ \\
\hline$I-134$ & 850 & 20 \\
\hline$I-135$ & 1280 & 1.5 \\
\hline$x e-135$ & 250 & 1.0 \\
\hline $\mathrm{Cs}-136$ & 818 & 15 \\
\hline $\mathrm{Cs}-137$ & 662 & 1.0 \\
\hline $\mathrm{Cs}-138$ & 1426 & 3 \\
\hline $\mathrm{Ba}-139$ & 166 & 1.0 \\
\hline $\mathrm{Ba}-140$ & 537 & 1.0 \\
\hline $\mathrm{La}-140$ & 1596 & 10 \\
\hline $\mathrm{La}-141$ & 1370 & 1.0 \\
\hline $\mathrm{Ce}-141$ & 145 & 1.0 \\
\hline La-142 & 650 & 15 \\
\hline $\mathrm{Ce}-143$ & 293 & 2.0 \\
\hline $\mathrm{Ce}-144$ & 135 & 1.0 \\
\hline Nd-147 & 531 & 1.0 \\
\hline $\mathrm{Nd}-149$ & 210 & 1.0 \\
\hline $\mathrm{Pm}-149$ & 286 & 1.0 \\
\hline$S m-153$ & 103 & 1.5 \\
\hline$S m-155$ & 104 & 1.1 \\
\hline$E u-155$ & 105 & 1.0 \\
\hline $\mathrm{Eu}-156$ & 646 & 15 \\
\hline$E u-157$ & 413 & 2 \\
\hline Gd-159 & 363 & 1.0 \\
\hline
\end{tabular}


BNWL -1285

TABLE 3. Inverse Reduction Factors for Environmental Radionuclides

\begin{tabular}{cccccc} 
Radionuclide & E, keV & $\begin{array}{c}\text { Inverse } \\
\text { Reduction } \\
\text { Factor, }\end{array}$ l/e & Radionuclide & E, keV & $\begin{array}{c}\text { Inverse } \\
\text { Reduction } \\
\text { Factor, l/e }\end{array}$ \\
\hline Be-7 & 477 & 1.0 & Rh-106 & 512 & 2 \\
Na-22 & 511 & 20 & Ag-110m & 658 & 50 \\
K-40 & 1460 & 1.0 & Sb-124 & 603 & 4 \\
Sc-46 & 889 & 7 & Sb-125 & 427 & 1.0 \\
Cr-51 & 320 & 1.0 & I-131 & 364 & 1.0 \\
Mn-54 & 835 & 1.0 & Cs-134 & 605 & 10 \\
Co-57 & 112 & 1.0 & Cs-137 & 662 & 1.0 \\
Co-58 & 810 & 1.2 & Ba-140 & 537 & 1.0 \\
Fe-59 & 1095 & 1.0 & La-140 & 1596 & 10 \\
Co-60 & 1173 & 7 & Ce-141 & 145 & 1.0 \\
Zn-65 & 1015 & 1.0 & Pr-144 & 695 & 1.2 \\
Y-88 & 898 & 6 & Ce-144 & 135 & 1.0 \\
Zr-95 & 724 & 1.0 & Eu-152 & 344 & 8 \\
Nb-95 & 765 & 1.0 & Eu-155 & 105 & 1.0 \\
Ru-103 & 497 & 1.0 & Bi-207 & 570 & 8
\end{tabular}

For example, ${ }^{46} \mathrm{Sc}$ has an $889 \mathrm{keV}$ gamma ray in coincidence with an $1120 \mathrm{keV}$ gamma ray. The gamma ray most likely measured under normal conditions would be the $889 \mathrm{keV}$ gamma ray because of the detectors greater efficiency for lower energy gamma rays. However, when this radionuclide is measured in an ACS-in system, the intensity of the $889 \mathrm{keV}$ peak will be reduced in the anticoincidence spectrum by an amount determined by the efficiency of the anticoincidence shield for detecting the $1120 \mathrm{keV}$ gamma ray. The efficiency of one anticoincidence shield for detecting $1120 \mathrm{keV}$ gamma rays is $86 \%$. (17) Thus $86 \%$ of the $889 \mathrm{keV}$ gamma rays would be stored in the coincidence spectrum and $14 \%$ in the anticoincidence spectrum yielding an inverse reduction factor for the measurement of ${ }^{46} \mathrm{Sc}$ in this particular ACS-in spectrometer of 7. Radionuclides with more than 2 gamma rays in cascade 
will have still greater reduction factors because each gamma ray has the possibibility of being detected in coincidence with more than one additional gamma ray.

In Figure 3, the number of radionuclides with a specific reduction factor are plotted versus the reciprocal of the peak reduction factor (1/e). [The reduction factors for all Ge(Li) Compton-summing system were calculated from the efficiency curves of Kraner and Chase. (14)] One survey included 85 radionuclides resulting from neutron activation with half lives greater than $2.5 \mathrm{~min}$ and the other included 40 of the most commonly found radionuclides in neutron activated material with half lives greater than $60 \mathrm{~min}$. A reduction factor of 1 means the full-energy peak intensity is not reduced by the Compton reduction process and the sensitivity for the measurement of this radioisotope will definitely be improved. Those radionuclides with inverse reduction factors greater than 10 cannot have improved detection sensitivities with either an anticoincidence-shielded system or the Compton-summing spectrometers since neither can provide background reductions greater than 100 in the region where they might obtain a peak reduction of 10. The sensitivity improvement for radionuclides with inverse reduction factors between 1 and 10 is uncertain and will depend on how much the background is reduced and the original peak-tobackground ratio.

The results of this survey of 85 radionuclides show that two-thirds of these radionuclides will definitely have improved sensitivities with the ACS-in system. On the other hand, the Compton-summing spectrometers cannot improve the sensitivity for over half of these radionuclides, and those with inverse reduction factors between 1 and 10 are in the uncertain category. This same trend is also evident for the more selective surveys shown in Figure 4, which include those radionuclides 

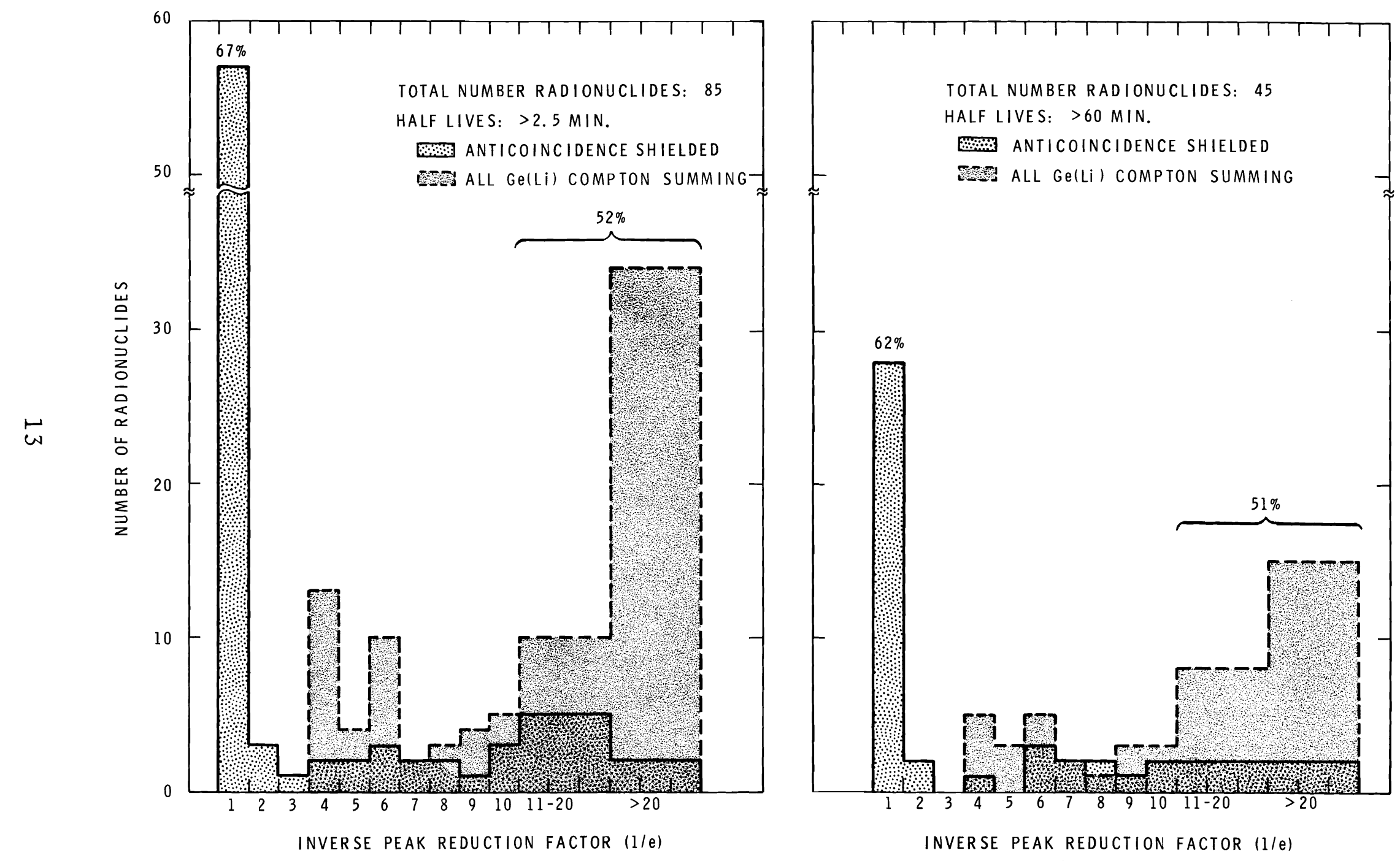

FIGURE 3. Frequency Distribution of the Inverse Full-Energy Peak Reduction Factors for Radionuclides Produced by Neutron Activation 
NEUTRON ACTIVATED GEOLOGICAL MATER IAL
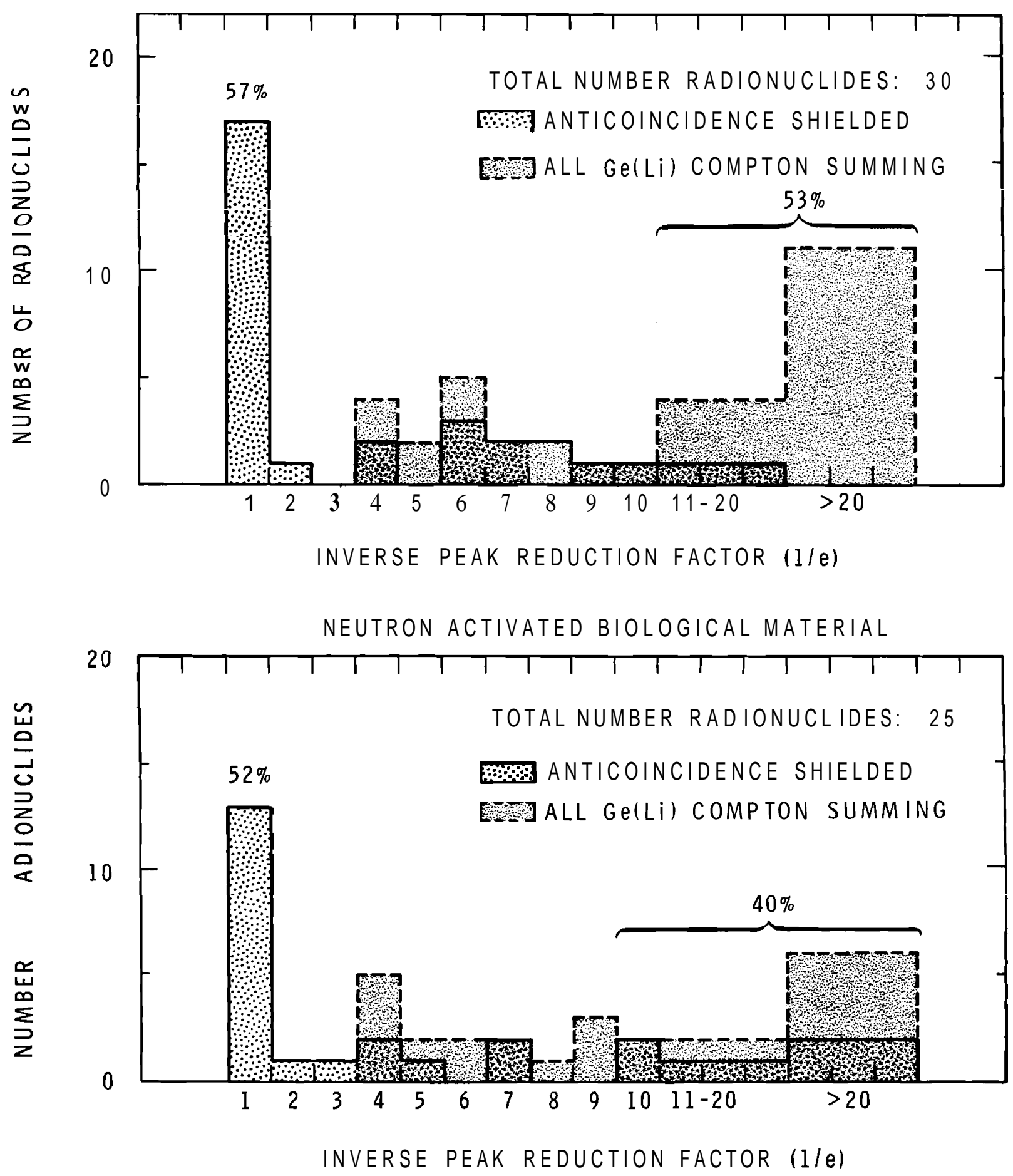

FIGURE 4. Frequency Distribution of the Inverse Full-Energy Peak Reduction Factors for Radionuclides Measured in Neutron Activated Geological and Biological Material 
commonly measured in neutron activated geological and biological material. The fission products listed in Table 2 show a similar trend, with two-thirds of these radionuclides having inverse reduction factors of 1 and therefore improved detection sensitivities with the ACS-in system.

The detection of radioactivity in low-level environmental samples requires not only a reduced compton continuum but also a maximum absolute peak efficiency and a minimum interference from natural background radiation. The only Ge(Li) detector system which fulfills all these requirements for most radionuclides in environmental and biological samples is the ACS-in spectrometer. A frequency distribution for the 30 most commonly measured radionuclides in environmental samples is presented in Figure 5. Again, almost two-thirds of the radionuclides, when measured on the ACS-in system, will have essentially no reduction in the full-energy peak efficiency. Thus, any reduction in the Compton continuum and natural background will improve the detection sensitivitv for these radionuclides. If the coincidence spectrum is also stored, (17) there will be no loss in the sensitivity for the measurement of the other one-third. However, it becomes questionable whether this sensitivity can be improved for radionuclides with inverse reduction factors greater than 2 in low-level samples.

The major disadvantage of the Compton-summing spectrometers is the large reduction in the full-energy peak intensity which accompanies the compton reduction. In addition, the absolute efficiency and resolution of these systems have not been equal to the state-of-the-art normal spectrometers which might be placed inside a Compton suppression shield. It is clear that they are not applicable to low-level counting and their application to high-level samples is questionable. They may be of practical value for the measurement of a few radionuclides in 
ENVIRONMENTAL RADIONUCLIDES

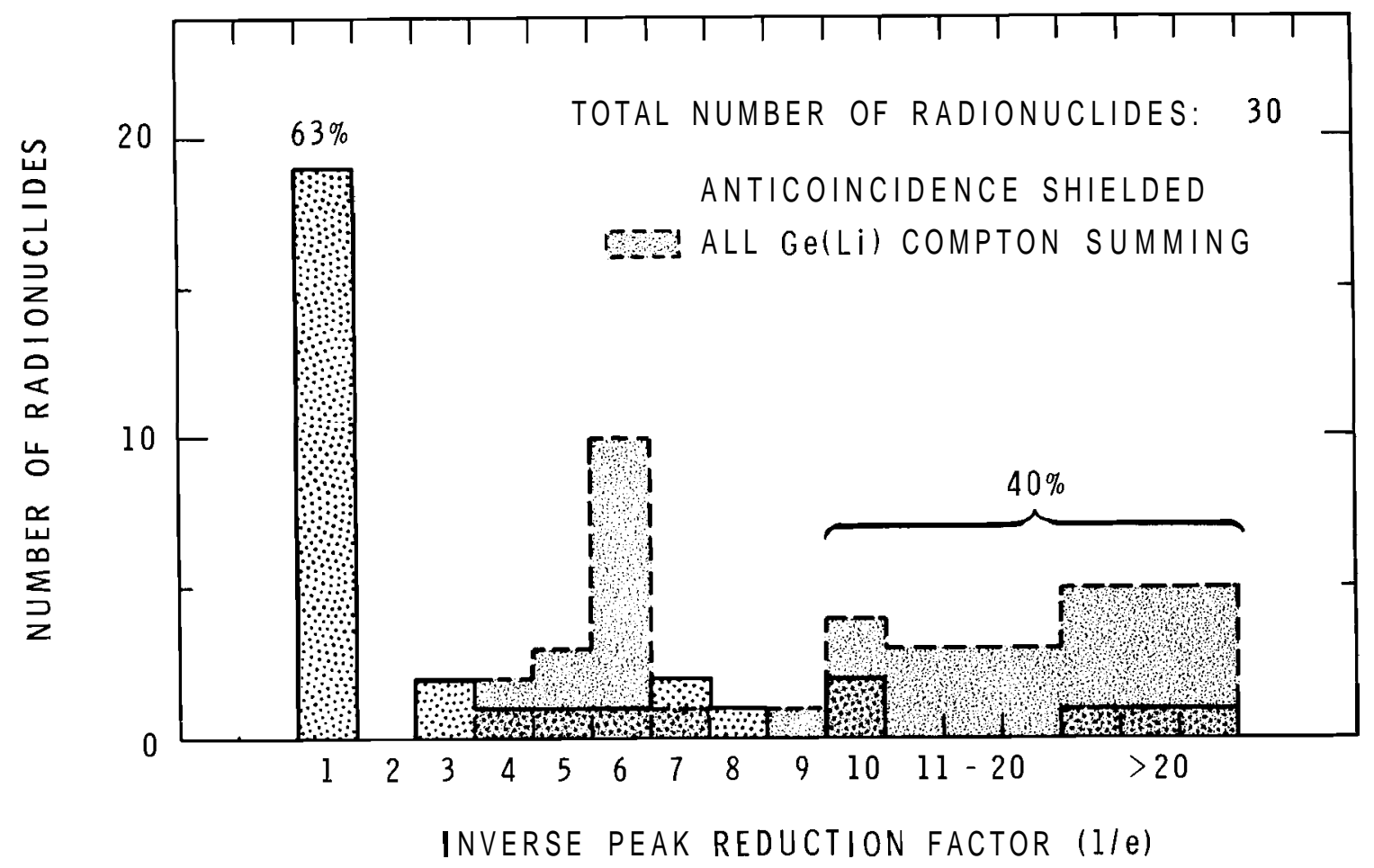

FIGURE 5. Frequency Distribution of the Inverse Full-Energy Peak Reduction Factors for Radionuclides Measured in Environmental Samples

a few specific examples, but are generally of little use to the analytical radiochemist in their present state of development and hold little promise for the future.

Those systems in which the source must be highly collimated and placed outside the shield are seriously limited by the 100-fold or more reduction in their absolute detection efficiency. In addition, the maximum compton reduction is presently only about 10. Although these systems are not of value for the measurement of radionuclides in low-level environmental samples, they are the best detection systems for the ultra-high intensity samples such as irradiated fuel elements and studies of decay schemes. The sensitivity for these problems in which the count rate is limited by the spectrometer's electronics depends on 
the intrinsic efficiency of the primary detector and not its absolute efficiency. Thus, the over 100-fold reduction in the geometrical efficiency for the ACS-out system is of little consequence for these samples. However, this is not the case for the a $11 \mathrm{Ge}(\mathrm{L} i)$ Compton-summing spectrometers and the ACS-in spectrometers because the rate of data accumulation is further restricted by the secondary detector. Although the count rate capabilities of the first diode in a Hick and Pepelnick(15) type Compton-summing spectrometer may be the same as a normal diode, the ultimate rate of data accumulation if further limited by the efficiency of the second diode to detect the gamma rays scattered from the first diode. The count rate of the ACS-in system is limited by the count rate capabilities of its shield and coincidence circuitry.

The ACS-in spectrometers are restricted to source intensities of less than about $1 \mu \mathrm{Ci}$. However, more intense sources can often be subdivided to provide a source of the proper intensity. In addition, more intense sources could be counted if the shield electronics and coincidence circuitry were improved.

An additional feature of the ACS-in system is its high inverse Compton reduction factors for radionuclides which decay by emission of coincident gamma rays. For these radionuclides, there exists a very high probability that the diode response to a gamma ray (either full energy or Compton) will be cancelled by the subsequent detection of the coincident gamma rays by the anticoincidence shield. This effect is more often than not an asset rather than a liability. Because of this feature, the ACS-in system is in some cases capable of providing an 80-fold reduction in the Compton interference without affecting the peak intensity of noncoincident gamma rays. (17)

\section{ACKNOWLEDGEMENTS}

I wish to thank R. W. Perkins, L. A. Rancitelli, and N. A. Wogman for their many helpful comments. 
BNWL -1285

\section{REFERENCES}

1. J. Kantele and P. Suominen. "A Ge(Li) Gamma Spectrometer Employing an Anti-Compton Mantze of NaI(TZ), "Nucl. Instr. and Methods, vol. 41, pp. 42-44. 2966.

2. W. Michaelis and H. Küpfer. "A High-Resolution Ge(Li) AntiCompton Spectrometer for Radiative Neutron Capture Spectroscopy," Nucl. Instr. and Methods, vol. 56, pp. 181-88. 1967.

3. V. J. Orphan and N. C. Rasmussen. "A Ge(Li) Spectrometer for Study Neutron Captive Gamma Rays," Nucl. Instr. and Methods, vol. 48, pp. 282-295. 1967.

4. D. C. Camp. Applications and Optimization of the LithiumDrifted Germanium Detector System, UCRL- 50156, p. 41.

Lawrence Radiation Laboratory, Liverrnore, California, March 3, 1967.

5. R. D. Cooper and G. L. BrownezZ. "A Large Coaxial Ge(Li) Detector with Plastic Anticoincidence Scintizzator for Activation Analysis," Nucl. Instr. and Methods, vol. 51, pp. $72-76.1967$.

6. R. L. Auble, D. B. Beery, G. Berzins, L. M. Beyer, R. C. Etherton, W. H. KeZzy, and Wm. C. MeHarris. "Coincidence-Anticoincidence Gamma-Ray Spectroscopy with a NaI(TZ) Split Annulus and a Ge(Li) Detector," Nucl. Instr. and Methods, vol. 51, p. 61. 1967.

7. Y. Sever and J. Lippert. "A Compton-Rejection Germanium Spectrometer," Nucl. Instr. and Methods, vol. 33, pp. 347348. 1965.

8. M. W. Hizz. "An Anticoincidence-Shielded Ge(Li) Gamma-Ray Spectrometer, " NucZ. Instr. and Methods, vol. 36, pp. $350-$ 352. 1965.

9. P. L. Phelps, K. O. Hamby, B. Shore, and G. D. Potter. Ge(Li) Gamma-Ray Spectrometers of High Sensitivity and Resolution for Biological and Environment Counting, UCRL 50437. Lawrence Radiation Laboratory, Liverrnore, California, May 1968.

10. J. Kantele and $P$. Suominen. "A Simple Summing Compton Ge(Li) Spectrometer, "Nucl. Instr. and Methods, vol. 56, pp. 351$354,1967$.

11. C. R. Gruhn, J. V. Kane, W. H. Kelly, T. Kuo, and G. Berzins. "A Single Crystal Ge(Li) Compton Spectrometer," Nucl. Instr. and Methods, vol. 54, pp. 268-276. 1967.

12. A. R. Sayres and J. A. Baicker. "The AlZ Germanium AntiCompton Spectrometer," IEEE Trans. Nucl. Sci., vol. 15, no. 3, pp. 393-396. 11th Seintizlation Semiconductor Counter Symp., June, 1968. 
BNWL -1285

13. J. M. Palms, R. E. Wood, and O. H. Puckett. "A Ge(Li) Concentric Diode Spectrometer for Compton Suppression," IEEE Trans. Nucl. Sci., vol. 15, no. 3, pp. 397. 11th Scintilzation Semiconductor Counter Symp., June 1968.

14. H. W. Kraner and R. L. Chase. "A Total Absorption Ge(Li) Gamma Ray Spectrometer," IEEE Trans. Nucl. Sci., vol. 15, no. 3, pp. 381-392. ScintizZation Semiconductor Counter Symp., June 1968.

15. H. Hick and R. Pepelnik. "Summing Ge(Li)-Compton Spectrometer with High Peak-to-Tail Ratio," NucZ. Instr. and Methods, vol. 68, pp. 240-244. 1969.

16. C. Broude, O. Häusser, H. MaZm, J. F. Sharpey-Schafer, and T. K. Alexander. "A Ge(Li) Two Crystal Compton Spectrometer," Nucl. Instr. and Methods, vol. 69, pp. 29-34. 1969.

17. J. A. Cooper, L. A. Rancitelzi, R. W. Perkins, W. A. Halzer, and A. L. Jackson. "Modern Trends in Activation Analysis," ed. by J. R. DeVoe, Nat. Bur. Std. Special Publ., 312, vol. 11, p. 1054. An Anticoincidence-Shield Ge(Li) GammaRay Spectrometer and Its Application to Neutron Activation Analysis, BNWL-SA-2009. Battelle-Northwest, Richland, Washington, August 2, 1968.

18. J. A. Cooper. Factors Determining the Ultimate Detection Sensitivity of Ge(Li) Gamma-Ray Spectrometers, BNWL-SA2940. Battelie-Northwest, Richland, Washington, November 1969.

19. D. C. Camp. Nuclear Spectroscopy via Ge(Li) Detectors in Compton Suppression and Pair Spectrometers, UCRL-71825. Lawrence Radiation Laboratory, Livermore, California, September 12, 1969.

20. R. B. GaZzoway. "Criteria for EvaZuating Background Suppression Techniques in Nuclear Spectroscopy Based on Consideration of Statistical Accuracy," Nucl. Instr. and Methods, vol. 55, pp. 29-33. 1967. 


\section{DISTRIBUTION}

No. of

Copies

OFFSITE

1

AEC Chicago Patent Group

G. H. Lee

212

AEC Division of Technical Information Extension

\section{ONSITE-HANFORD}

1

AEC Chicago Patent Group

R. K. Sharp (Richland)

1 AEC Richland Operations Office

C. L. Robinson

3 Battelle Memorial Institute

2 RDT Assistant Director for Pacific Northwest Programs

39 Battelle-Northwest

E. L. Alpen

J. A. Cooper (25)

J. M. Nielsen

N. A. Wogman (5)

Technical Information (5)

Technical Publications (2) 